\title{
COMPUTATIONAL FLUID DYNAMICS PRESSURE WAVE AND FLOW RATE ANALYSIS OF INTAKE RUNNER DESIGN IN INTERNAL COMBUSTION ENGINE
}

\author{
Karlis Banis \\ Latvia University of Life Sciences and Technologies, Latvia \\ k.banis@yahoo.com
}

\begin{abstract}
This paper investigates the effect of intake runner design on pressure wave propagation and reflection in sparkignited internal combustion (IC) engine. These events are known to leave a noticeable influence on the overall engine performance therefore the aim of this study is to evaluate how changes in intake runner geometry affect pressure oscillations and volume flow rate. Time-dependent computational fluid dynamics (CFD) analysis was carried out to determine how these changes affect the pressure oscillations during a full engine cycle at constant crankshaft speed. Steady state CFD analysis at constant pressure differential was carried out to evaluate the effect on volume flow rate. The simulations were carried out in SolidWorks Flow Simulation environment. Honda CRF450R motorcycle engine was used to define the initial conditions and basic intake runner design. Intake air speed at port entrance cross-section was calculated based on engine parameters and operating speed. The average pressure values with respect to physical time were measured and graphed across the intake port opening cross-section. Six different intake runner designs were compared. It was concluded that the runner taper angle has influence on pressure wave-length but internal geometry (steps, curvature and taper angle) has influence on volume flow rate. It was observed that cylindrical intake runner design produced an increase in pressure wave-length but a cylindrical section of the intake runner with a stepped transition to tapered extension produced a slight increase in pressure wave amplitude.
\end{abstract}

Key words: computational fluid dynamics, flow simulation, pressure waves, intake system, volumetric efficiency.

\section{Introduction}

Modern internal combustion engines require highly tuned components and systems to achieve the benchmark that meets the market requirements for fuel consumption, emissions and output. The goal of these components and systems is to maximize the efficiency of the engine by increasing the volumetric efficiency and creating optimum conditions for a clean combustion process. The typical spark-ignition internal combustion (IC) engine (see Fig. 1, Table 1 ) is equipped with an intake system that consists of intake runner, plenum and throttle body. The layout of this system has a great influence on the torque curve described as the engine output (Bayas, Wankar, \& Jadhav, 2016). In addition, smaller changes in runner design can help performance by decreasing the flow resistance and modifying the pressure oscillations created by cyclic intake strokes of the piston (Hamilton, Cowart, \& Rozich, 2009). According to previous research done in this field, propagating pressure waves in fluids will reflect from open or closed areas, including changes in the cross section of propagation path (Soon, 2014). When low pressure is generated near the intake valve(s) by the piston, the intake cycle begins and the fluid in the intake runner starts flowing into the cylinder while building momentum and generating a negative pressure wave front at the same time. When the intake valve(s) is closing, the fluid in the intake runner is transferring its kinetic energy to pressure generating a positive pressure wave front traveling at the local speed of sound and propagating back in the direction of the inlet boundary or plenum. When the wave front reaches the inlet boundary, some portion of the pressure wave will be reflected back into the intake runner. It has been found that pressure oscillations in the intake runner are, to a certain extent, unaffected by the acoustics of the intake plenum (Selamet, Kothamasu, \& Novak, 2001). This back-and-forth propagation of the pressure wave fronts in the intake runner is responsible for maximizing the efficiency of the ongoing and creating optimum conditions for the next intake cycle. This allows the volumetric efficiency to be increased beyond the region that an intake system with no runner can achieve (Sammut \& Alkidas, 2007). The goal of a tuned intake system is to ensure the pressure oscillation frequency that aids engine breathing at the desired engine speed of maximum output and to maintain the maximum possible amplitude of the pressure oscillations to yield the most effect. It is also important to design the intake system in such a way as to provide the lowest possible flow resistance while keeping the flow characteristics sufficient for optimum combustion process. In addition, intake and exhaust wave reflection points can be paired or offset to compliment one another and enhance the scavenging process (Vorum, 1980). Nowadays, numerical (1D) or acoustics simulation software can be employed to estimate the optimum intake runner length or geometry, significantly reducing the time for engine development and testing (Vítek \& Polášek, 2002). It has been found that good agreement between mathematical models and real-time measurement can be achieved (Harrison, De Soto, \& Unzueta, 2004). These models can be supplemented to account for intake and exhaust interaction to allow a more detailed prediction of engine performance (Zhang \& Assanis, 2003). 


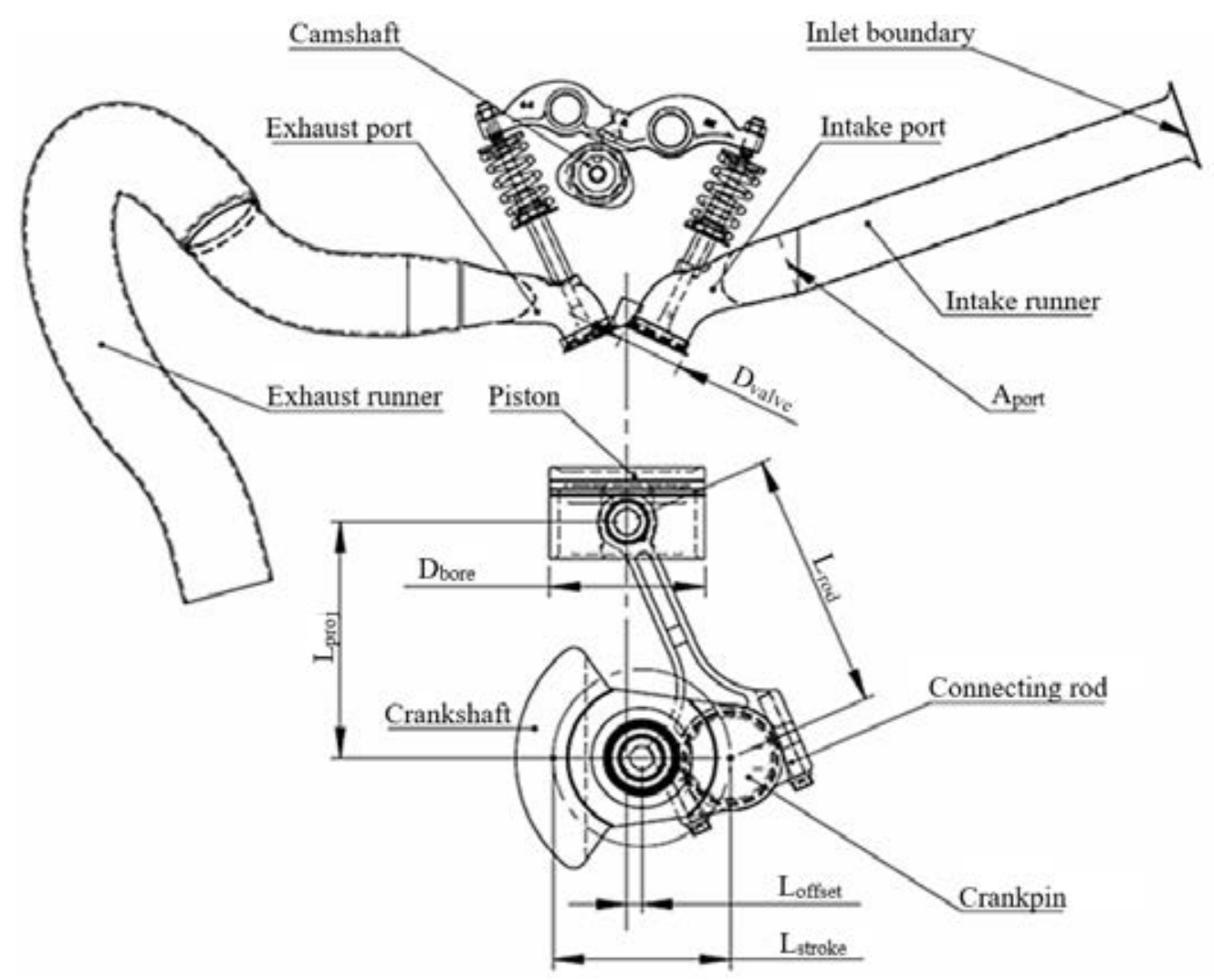

Figure 1. Main components of internal combustion engine (see Table 1 for abbreviations).

\section{Engine and calculation parameters}

Table 1

\begin{tabular}{|c|c|c|}
\hline Parameter & Abbreviation & Value \\
\hline Bore, mm & $\mathrm{D}_{\text {bore }}$ & 96.0 \\
\hline Stroke, $\mathrm{mm}$ & $\mathrm{L}_{\text {stroke }}$ & 61.9 \\
\hline Connecting rod length, mm & $\mathrm{L}_{\text {rod }}$ & 102.3 \\
\hline Cylinder offset, mm & $\mathrm{L}_{\text {offset }}$ & 8.0 \\
\hline Swept volume, $\mathrm{cm}^{3}$ & - & 449.4 \\
\hline Intake valve diameter, $\mathrm{mm}$ & $\mathrm{D}_{\text {valve }}$ & 36.0 \\
\hline Intake lift duration, ${ }^{\circ} \mathrm{Crankshaft}$ & - & 180 \\
\hline Intake port opening area, $\mathrm{mm}^{2}$ & $A_{\text {port }}$ & 1452.2 \\
\hline Analysis engine speed, $\min ^{-1}$ & - & 10000 \\
\hline Volumetric efficiency at the speed of analysis, $\%$ & $\mathrm{VE}$ & 100 \\
\hline Angular step, ${ }^{\circ}$ & $t_{\mathrm{deg}}$ & 4 \\
\hline Time step, s & $\mathrm{t}_{\mathrm{sec}}$ & $6.6710^{-4}$ \\
\hline Crankshaft angular position, ${ }^{\circ}$ & $P_{\text {crank }}$ & $0-360$ \\
\hline Crankpin horizontal displacement, mm & $\mathrm{L}_{\mathrm{x}}$ & - \\
\hline Crankpin vertical displacement, $\mathrm{mm}$ & $\mathrm{L}_{\mathrm{v}}$ & - \\
\hline Connecting rod projection, mm & $\mathrm{L}_{\text {proj }}$ & - \\
\hline Absolute piston position, mm & $P_{\text {abs }}$ & - \\
\hline Relative piston position, mm & $\mathrm{P}_{\text {rel }}$ & - \\
\hline Cylinder volume, $\mathrm{cm}^{3}$ & $\mathrm{~V}_{\mathrm{cyl}}$ & - \\
\hline Filling speed, $\mathrm{cm}^{3} \mathrm{~s}^{-1}$ & $\mathrm{~S}_{\text {fill }}$ & - \\
\hline Intake valve lift, mm & $\mathrm{L}_{\text {valve }}$ & 一 \\
\hline Air speed at port opening, $\mathrm{m} \mathrm{s}^{-1}$ & $\mathrm{~S}_{\text {air }}$ & - \\
\hline
\end{tabular}




\section{Materials and Methods}

The object of the investigation is a basic intake runner design from 2013 Honda CRF450R motorcycle, supplemented with constructional changes associated with different throttle body housing designs. The analysis was carried out in 2018 at the premises of Latvia University of Life Sciences and Technologies in SolidWorks Flow Simulation computational fluid dynamics (CFD) environment using NavierStokes equations as a basis and supplementing the calculation with geometry, boundary, wall and initial conditions. The boundary conditions are calculated based on engine parameters (see Table 1) and operating conditions are introduced on six different intake runner layouts (see Fig. 2 and Table 2). The calculation is done with respect to physical time and with the use of nested iterations to allow the mapping of pressure waves inside the runner. The results are obtained numerically and presented in a table reflected by a graph.

The boundary conditions are derived from the engine operating at a constant speed that coincides with the engine speed of maximum aimed power output. Atmospheric pressure boundary condition is specified inside the inlet chamber and outlet air speed is specified at the runner outlet. The overall length of the model coincides with that of the given engine from intake valves to the inlet boundary (see Fig. 1, Table 2).

In order to calculate the outlet air speed, it is necessary to plot the piston position with respect to the angular position of the crankshaft. It can be calculated by dividing the location of the crankpin in horizontal $\left(\mathrm{L}_{\mathrm{x}}\right)$ and vertical $\left(\mathrm{L}_{\mathrm{y}}\right)$ components (Equations (1) and

A)

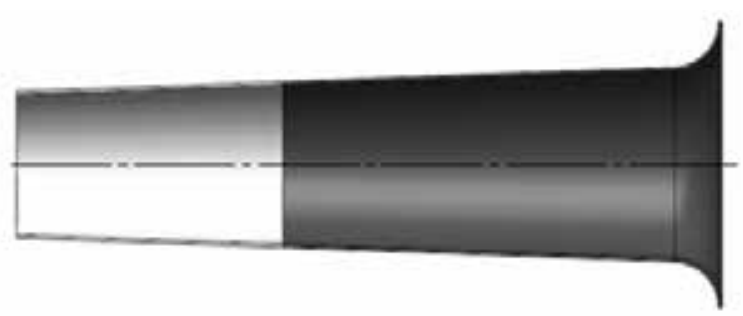

B)

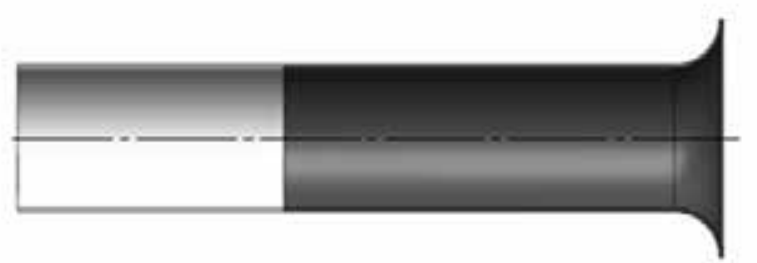

C)

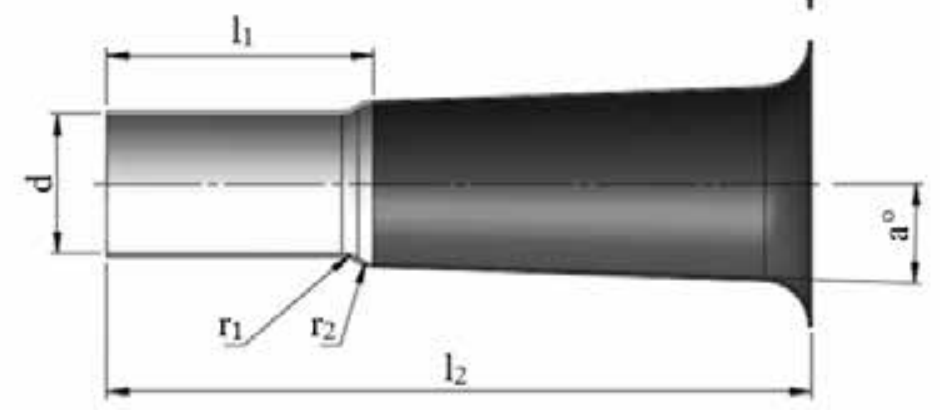

Figure 2. Intake runner designs of the study.

\section{Runner design parameters}

Table 2

\begin{tabular}{|c|c|c|c|c|c|c|}
\hline Variant & $\mathrm{D}, \mathrm{mm}$ & $\mathrm{l}_{1}, \mathrm{~mm}$ & $\mathrm{l}_{2}, \mathrm{~mm}$ & $\mathrm{r}_{1}, \mathrm{~mm}$ & $\mathrm{r}_{2}, \mathrm{~mm}$ & $a^{\circ}$ \\
\hline A (OE design) & \multirow{6}{*}{43} & \multirow{6}{*}{217} & \multirow{6}{*}{82} & - & - & 2.1 \\
\hline B & & & & - & - & 0 \\
\hline $\mathrm{C}$ & & & & 0 & 0 & 2.1 \\
\hline $\mathrm{C}_{1}$ & & & & 3 & 15 & 2.1 \\
\hline $\mathrm{C}_{2}$ & & & & 9 & 9 & 2.1 \\
\hline $\mathrm{C}_{3}$ & & & & 15 & 6 & 2.1 \\
\hline
\end{tabular}




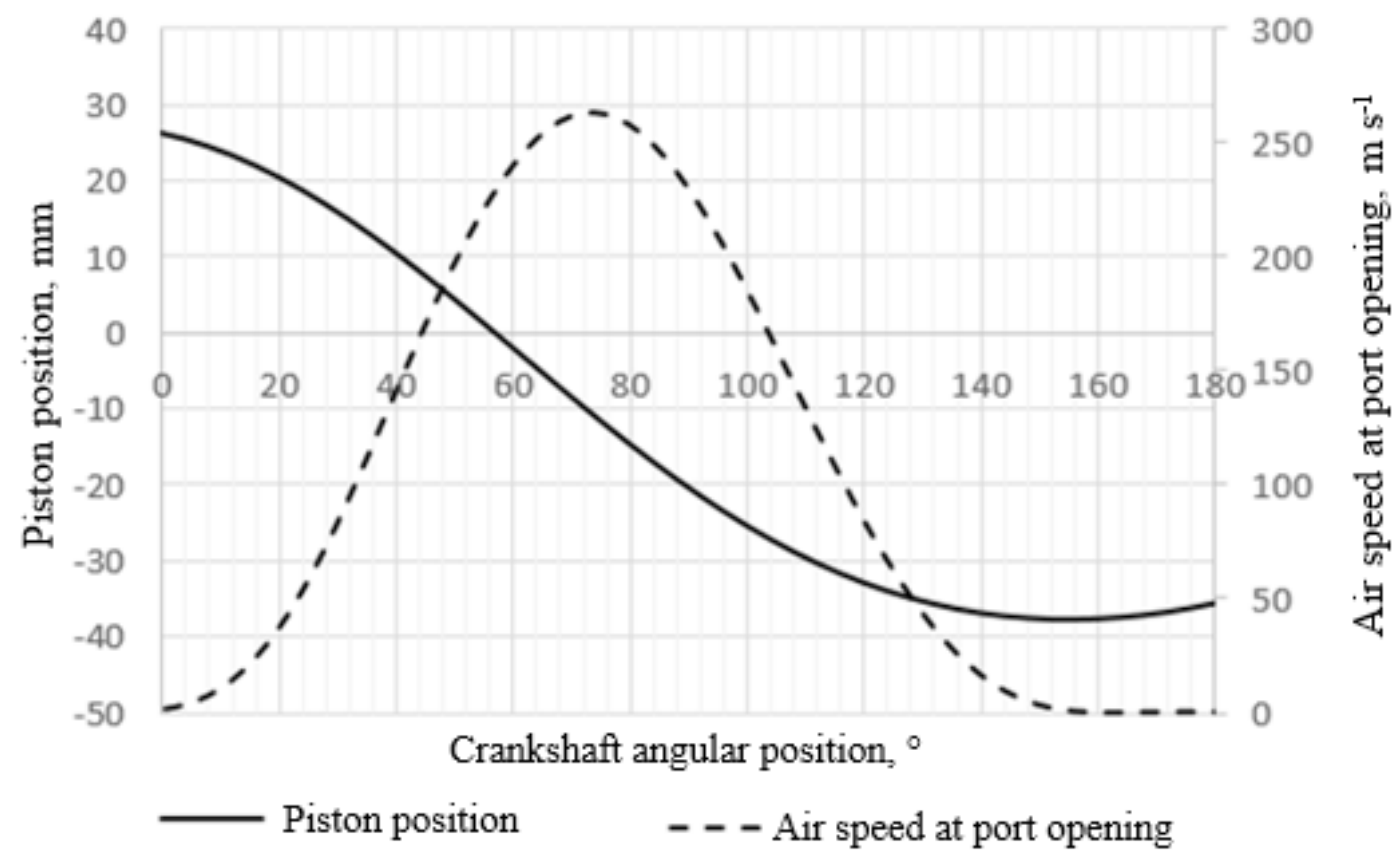

Figure 3. Calculated values of air speed $\mathrm{S}_{\text {air }}$ and relative piston position $\mathrm{P}_{\text {rel }}$ with respect to crankshaft angular position $\mathrm{P}_{\text {crank }}$.

(2)). The crankshaft angular position step $\mathrm{t}_{\mathrm{deg}}=4^{\circ}$ (see Table 1 and Fig. 1 for abbreviations).

$$
\begin{aligned}
L_{x_{i}} & =\frac{\sin \left(P_{\text {crank }_{i}}\right) \cdot L_{\text {stroke }}}{2} \\
L_{y_{i}} & =\frac{\cos \left(P_{\text {crank }_{i}}\right) \cdot L_{\text {stroke }}}{2}
\end{aligned}
$$

As the connecting rod is changing the angle from vertical axis with respect to the angular position of the crankshaft, it is necessary to calculate the length of its vertical projection $L_{\text {proj }}$, considering the offset $\left(L_{\text {offset }}\right)$ between the cylinder axis and center of crankshaft (see Equation 3).

$$
L_{\text {proj }_{i}}=\sqrt{L_{\text {rod }}^{2}-\left(L_{x_{i}}+L_{o f f s e t}\right)^{2}}
$$

The absolute position of the piston $\mathrm{P}_{\mathrm{abs}}$ can then be expressed as the difference between the vertical projection of connecting $L_{\text {proj }}$ and its length $L_{\text {rod }}$ subtracted from the crankpin's vertical component $\mathrm{L}_{\mathrm{y}}$ (see Equation 4).

$$
P_{a b s_{i}}=L_{y_{i}}-\left(L_{\text {rod }}-L_{\operatorname{proj}_{i}}\right)
$$

The following expression (see Equation 5) translates the piston position from absolute $\left(\mathrm{P}_{\mathrm{abs}}\right)$ to relative $\left(\mathrm{P}_{\text {rel }}\right)$. The result of this variable is plotted in Figure 3.

$$
P_{r e l_{i}}=P_{a b s_{i}}-P_{a b s_{\text {min }}}
$$

The volume of the cylinder $\mathrm{V}_{\text {cyl }}$ in each respective angular position of the crankshaft can now be expressed as follows (see Equation 6).

$$
V_{c y l_{i}}=\frac{\pi \cdot D_{\text {bore }^{2}}}{4} \cdot P_{\text {rel }_{i}} \cdot 10^{-3} \cdot V E
$$

The cylinder filling speed $\mathrm{S}_{\text {fill }}$ is now the difference of two cylinder volumes at adjacent time steps over the amount of time step (see Equation 7).

$$
S_{\text {fill }_{i}}=\frac{V_{c y l_{i+1}}-V_{c y l_{i}}}{t_{\text {sec }}}
$$

Due to the constraints of this study, the intake valve lift duration is limited to 180 degrees of crankshaft rotation, with the opening and closing events coinciding with the beginning and end of intake stroke. The valve lift profile is generated automatically by a dedicated software to produce a smooth curve. Finally, the simulation air speed at port opening $S_{\text {air }}$ is expressed in Equation 8 (see Fig. 3 for result).

$$
S_{\text {air } i}=\frac{S_{\text {fill }_{i}} \cdot 10^{-2}}{A_{\text {port }}} \cdot \frac{L_{\text {valve }_{i}}}{\bar{X} \sum L_{\text {valve }}}
$$

The CFD calculations are performed using timedependent analysis type. The time interval is equal to that of a full Otto cycle at the engine speed of maximum output $-10000 \mathrm{~min}^{-1}$. The geometry mesh is generated by equidistant approach with refined resolution in the area of concern (see Fig. 4). 


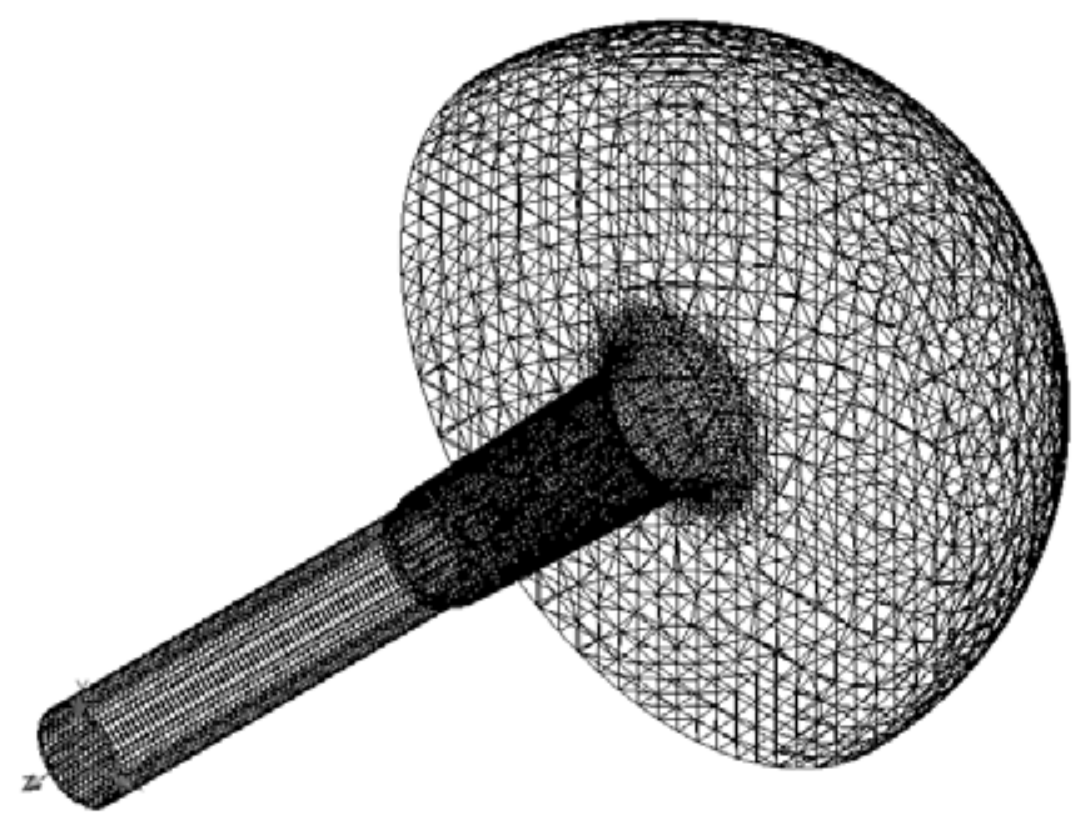

Figure 4. Mesh of intake runner and inlet chamber geometry.

Simulation parameters: total time $-12 \cdot 10^{-2} \mathrm{~s}$, fluid - air, temperature $-20{ }^{\circ} \mathrm{C}$, humidity $-50 \%$, surface roughness - $10 \mu \mathrm{m}$, inlet pressure -101.325 $\mathrm{KPa}$, outlet $-\mathrm{S}_{\text {air }}$ (see Table 1, Equation (8), Fig. 3).

\section{Results and Discussion}

The results, according to the phenomenon described in the introduction section, are showing pressure oscillations that gradually decrease over time (see Table 3 and Fig. 5). At physical time 31 . $10^{-3} \mathrm{~s}$ the intake valve is fully closed, forcing the runner pressure to reach peak value and producing the said oscillations in the form of a wave. The greatest deviation between intake runner designs with respect to pressure wave-length is observed in cases that differ in overall geometry (A, B and $\mathrm{C}$ ), rather than the radius of curvature, if present $\left(C, C_{1}, C_{2}\right.$, and $\mathrm{C}_{3}$ ). The taper angle (Fig. $2-\mathrm{a}$ ), by producing a shorter pressure wave-length, is exhibiting an effect that is associated with shortening of the intake runner centerline length aiding engine breathing at higher crankshaft speeds (Ceviz \& Akın, 2010). The volume flow rates prove similar across designs $\mathrm{A}$, $\mathrm{C}_{1}, \mathrm{C}_{2}$ and $\mathrm{C}_{3}$, and suffer in designs $\mathrm{B}$ and $\mathrm{C}$ due to increases in flow resistance. This can be attributed to the curvature of the geometry and flow friction in the boundary layer. The slight increase observed in pressure wave amplitude in designs $C_{1}, C_{2}$, and $C_{3}$ approves the findings in the previous research where it was concluded that multiple reflections of a positive pressure wave significantly enhance engine breathing (Hamilton, Cowart, \& Rozich, 2009). The additional positive pressure wave reflection point in runner designs $\mathrm{C}_{1}, \mathrm{C}_{2}$, and $\mathrm{C}_{3}$ can be considered as the area in vicinity of variables $r_{1}$ and $r_{2}$ (see Fig. 2) producing a change in cross-section of the flow path (Soon, 2014).

Flow simulation results

\begin{tabular}{|l|c|c|c|c|}
\hline & $\begin{array}{c}\text { Volume flow rate, } \\
\mathrm{l} \mathrm{min}^{-1}\end{array}$ & Max pressure, KPa & Min pressure, KPa & $\begin{array}{c}\text { Total pressure area, } \\
\text { KPa s }\end{array}$ \\
\hline A (OE design) & 8743 & 66.54 & -64.46 & 0.3214 \\
\hline B & 8283 & 64.08 & -66.52 & 0.3336 \\
\hline C & 7929 & 63.97 & -65.39 & 0.3049 \\
\hline$C_{1}$ & 8509 & 68.26 & -65.31 & 0.3221 \\
\hline$C_{2}$ & 8604 & 68.71 & -65.24 & 0.3238 \\
\hline$C_{3}$ & 8655 & 68.80 & -65.25 & 0.3243 \\
\hline
\end{tabular}




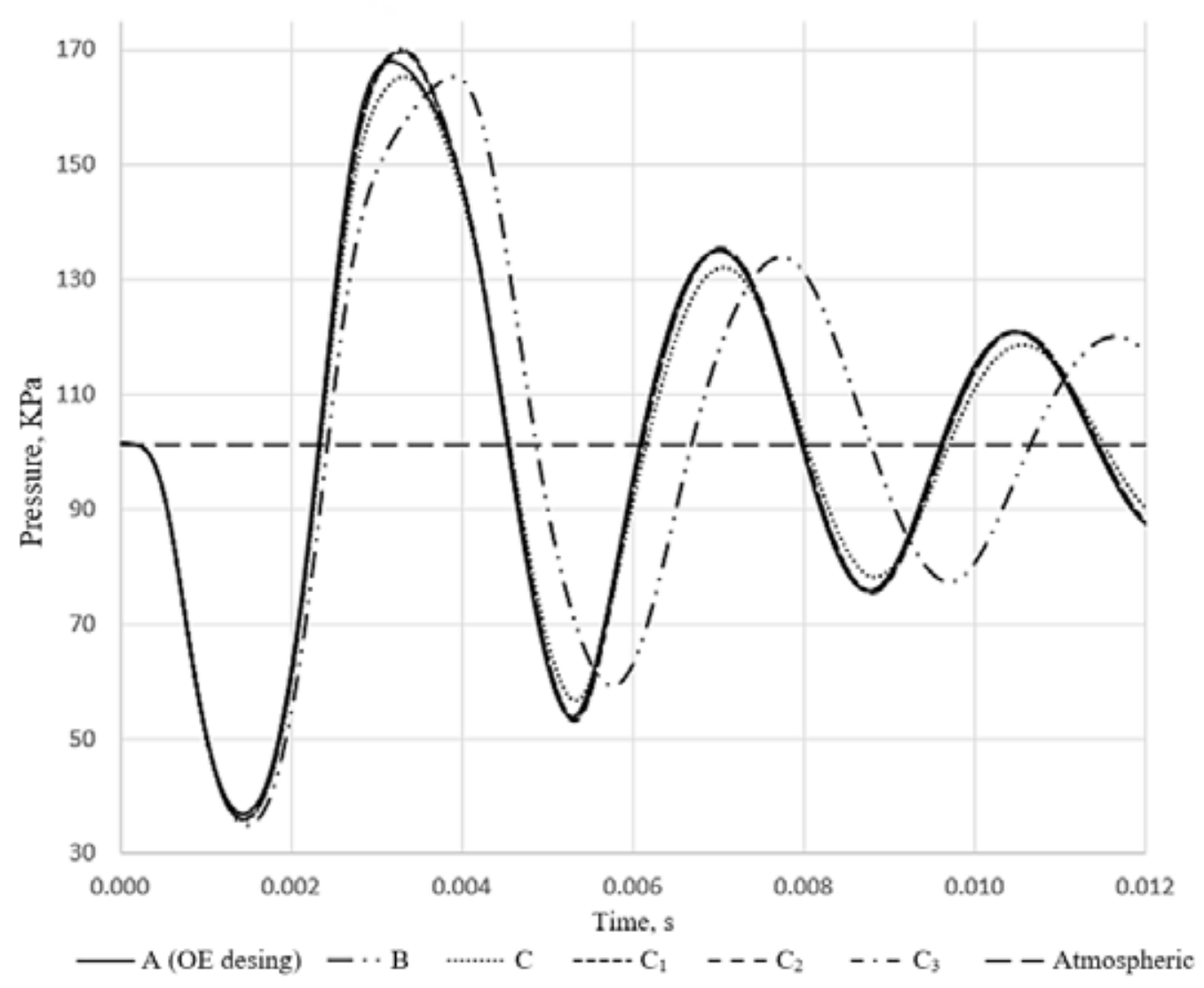

Figure 5. Dynamic flow simulation results - intake runner pressures.

\section{Conclusions}

1. Design $B$ produced the longest pressure wavelength due to cylindrical geometry $\left(a=0^{\circ}\right)$ while maintaining the pressure amplitude similar to OE design ( $0.4 \%$ lower) but suffering notably from lack of volume flow rate $(-5.3 \%)$ whereas design $\mathrm{C}$, even though similar to $\mathrm{C}_{1}, \mathrm{C}_{2}$ and $\mathrm{C}_{3}$, suffers from severely reduced volume flow rate $(-9.3 \%)$ due to the sharp edges $\left(r_{1}\right.$ and $\left.r_{2}=0 \mathrm{~mm}\right)$ in geometry, exhibiting a tendency of apparent slight runner shortening effect.

2. Designs $\mathrm{C}_{1}, \mathrm{C}_{2}$ and $\mathrm{C}_{3}$ were observed to produce the highest pressure amplitudes while maintaining minimal volume flow rate loss, indicating the possibility to reach slightly higher volumetric efficiencies. The increase of $r_{1}$ and $r_{2}$ in designs $\mathrm{C}_{1}, \mathrm{C}_{2}$ and $\mathrm{C}_{3}$ tends to increase the volume flow rate while resulting in higher pressure amplitudes where $\mathrm{C}_{3}$ proved to be the overall best of $\mathrm{C}$ subdesigns, providing a pressure amplitude of 134.05 $\mathrm{KPa}$ (1\% higher compared to OE design) but slightly losing in volume flow rate compared to OE design (1\% lower).

3. To fully evaluate if these changes translate to an increase in volumetric efficiency, it is necessary to test the engine on a dynamometer.

\section{References}

1. Bayas, J., Wankar, A., \& Jadhav, N.P. (2016). A Review Paper on Effect of Intake Manifold Geometry on Performance of IC Engine. International Journal of Advance Research and Innovative Ideas in Education, 2(2), 101-106.

2. Ceviz, M.A., \& Akın, M. (2010). Design of a New SI Engine Intake Manifold with Variable Length plenum. Energy Conversion and Management, 51(11), 2239-2244. DOI: 10.1016/j.enconman.2010.03.018.

3. Hamilton, L.J., Cowart, J., \& Rozich, J. (2009). The Effects of Intake Geometry on SI Engine Performance. SAE Technical Paper 2009-01-0302. DOI: 10.4271/2009-01-0302.

4. Harrison, M.F., De Soto, I., \& Unzueta, P.R. (2004). A Linear Acoustic Model for Multi-Cylinder IC Engine Intake Manifolds Including the Effects of the Intake Throttle. Journal of Sound and Vibration, 278(4-5), 975-1011. DOI: 10.1016/j.jsv.2003.12.009.

5. Sammut, G., \& Alkidas, A.C. (2007). Relative Contributions of Intake and Exhaust Tuning on SI Engine Breathing - A Computational Study. SAE Technical Paper 2007-01-0492. DOI: 10.4271/2007-01-0492. 
6. Selamet, A., Kothamasu, V., \& Novak, J.M. (2001). Insertion loss of a Helmholtz Resonator in the Intake System of Internal Combustion Engines: An Experimental and Computational Investigation. Applied Acoustics, 62(4), 381-409. DOI: 10.1016/S0003-682X(00)00042-6.

7. Soon, K.A. (2014). Simulation and Experimental Studies of Intake and Exhaust Tuning for Automotive Engine Low-End Torque Enhancement. Master's thesis. University of Science Malaysia, Penang, Malaysia.

8. Vítek, O., \& Polášek, M. (2002). Tuned Manifold Systems - Application of 1-D Pipe Model. SAE Technical Paper 2002-01-0004. DOI: 10.4271/2002-01-0004.

9. Vorum, P.C. (1980). Short Pipe Manifold Design for Four-Stroke Engines. Journal of Engineering for Power. 102(4).

10. Zhang, G.Q., \& Assanis, D.N. (2003). Manifold Gas Dynamics Modeling and Its Coupling with SingleCylinder Engine Models Using Simulink. Journal of Engineering for Gas Turbines and Power, 125(2), 563-571. DOI: 10.1115/1.1560708. 